\title{
Red Carbon: a Carbon-Oxygen-based covalent semiconductor for selective amine sensing
}

\author{
Paolo Giusto*, Daniel Cruz, Yael Rodriguez, Regina Rothe,
}

\section{Nadezda Tarakina}

\section{Abstract}

The requirements for organic semiconductor materials and new methods for their synthesis at low temperature have risen over the last decades, especially due to concerns of sustainability. Herein, we present an innovative method for the synthesis of a so-called "red carbon" thin film, being composed of carbon and oxygen, only. This material was already described by Kappe and Ziegler at the beginning of the $20^{\text {th }}$ century, but now can complement the current research on covalent organic semiconductor materials. The herein described red carbon can be homogeneous deposited on glass substrates as thin ilms which reveal a highly ordered structure. The films are highly reactive towards amines and were employed as amine vapor sensors for a scope of analogous amines. The gasto-solid phase reaction causes a significant change of the films optical properties in all cases, blue-shifting the bandgap and the photoluminescence spectra from the red to the near UV range. The irreversible chemical reaction between the thin film and the vapor was also exploited for the preparation of nitrogen containing thin carbon films. We expect the herein presented red carbon material is of interest not only for sensing applications, but also in optoelectronics. 


\section{Introduction}

The increased requirements for highly performing devices raised during the last years concerns regarding the supply of raw materials, especially regarding rare metals and semiconductors. For this reason, our research focused in the development of new, highly efficient materials based on carbon. The development of new synthetic techniques and the strong advances in characterization methods enabled a new era in materials science, around carbon. From the beginning of the XXI century, the development of graphene, nanotubes and fullerenes have boosted this research, with particular focus on 2D covalent graphitic-like structures. Later on, the introduction of heteroatoms in these graphitic frameworks have paved the way for the development of high performing materials in a wide range of applications and devices. Among those, the introduction of nitrogen in certain fashions was proven to boost conductivity and oxidation stability, even increasing the Fermi level above the level of noble metals, nowadays commonly referred to as "Noble Carbons". ${ }^{1-2}$ Old materials as carbon nitride made a strong comeback, and new materials classes with extraordinary properties were explored, such as ternary boron carbon nitrides, $\mathrm{C}_{2} \mathrm{~N}$ and more. ${ }^{3-8}$ Recent research focused especially on the introduction of nitrogen into covalent $\mathrm{sp}^{2}$-hybridized structures, with less attention paid to materials composed of carbon and oxygen. ${ }^{1-2,4-5,7,9-11}$

The broadly known carbon oxides are carbon monoxide $(\mathrm{CO})$ and carbon dioxide $\left(\mathrm{CO}_{2}\right)$ are gases. However, there are countless more carbon oxide compounds, among the linear carbon dioxides, with the general formula $\mathrm{C}_{n} \mathrm{O}_{2}(n \geq 1)$. Among those, carbon suboxide (C3O2) was already an industrial product used at the ton scale in the early $20^{\text {th }}$ century and attracted attention as a highly reactive synthon for the synthesis of 
heterocycles and malonyl derivatives. ${ }^{12-13} \mathrm{C}_{3} \mathrm{O}_{2}$ behaves alike a bisketene, and was described by Kappe and Ziegler as a double dehydrated malonic acid. ${ }^{13}$

First reports on higher carbon oxides date back to Brodie in 1873, when he exposed carbon monoxide to an electric current and reported on the formation of $\mathrm{CO}_{2}$ and a redbrown film deposition on the reactor walls. Further analysis these films led to the conclusion that the compounds were oxides of carbon possibly belonging to a series, analogous to the series of hydrocarbons, which he named "oxycarbons". ${ }^{14-15}$ This report has inspired further research by Diels and Wolf, who in 1906 were able to isolate and characterize carbon suboxide $\left(\mathrm{C}_{3} \mathrm{O}_{2}\right)$ obtained from the dehydration of diethyl malonate by large excess of $\mathrm{P}_{2} \mathrm{O}_{5}$ at $300^{\circ} \mathrm{C}$. In last century, further methods for the synthesis of carbon suboxide have been implemented, and summarized in the following (Fig. 1). ${ }^{13,} 16$
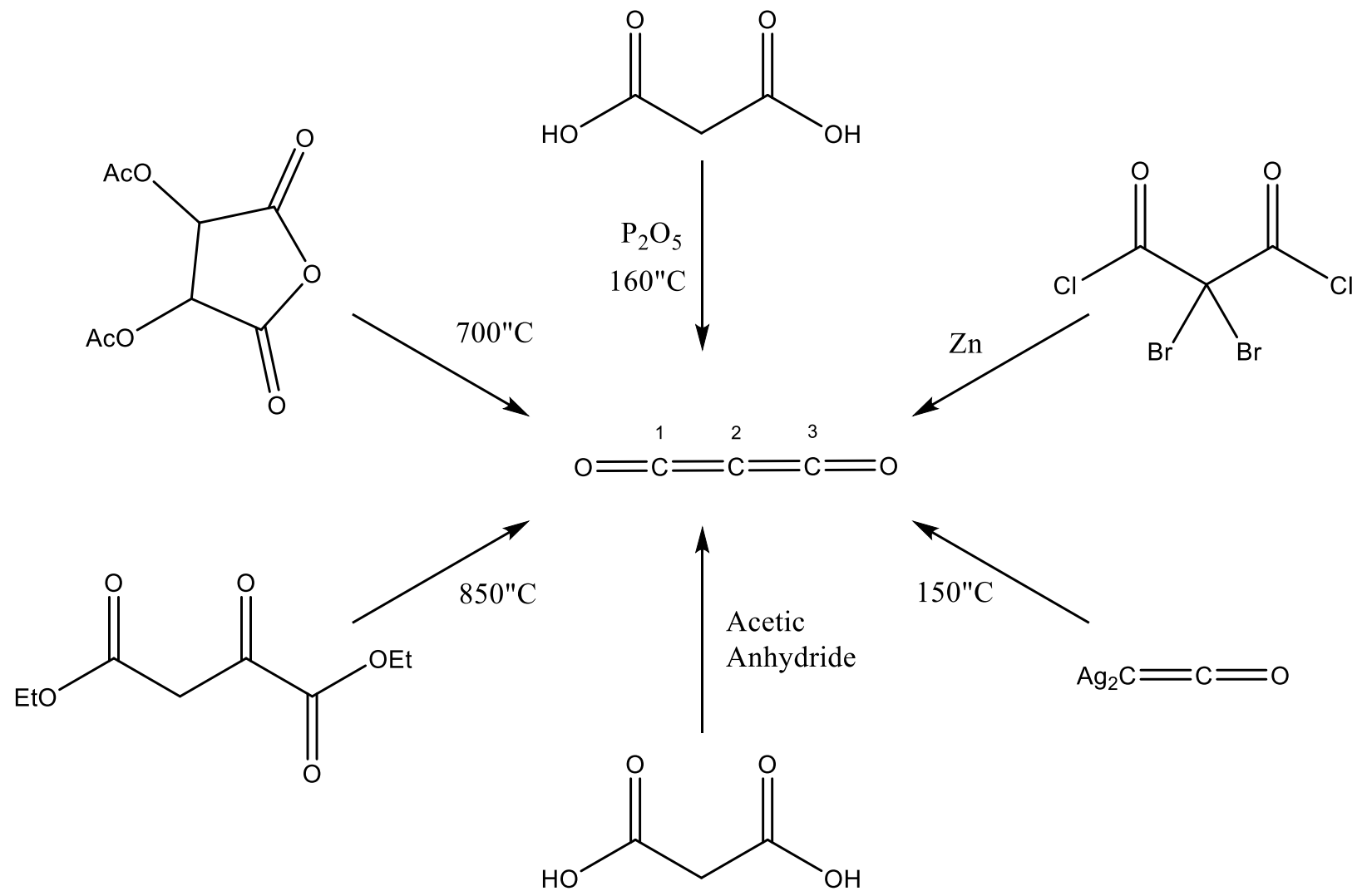

Figure 1. Summary of synthetic methods for carbon suboxide synthesis. 
Carbon suboxide is a metastable gaseous molecule with low melting $\left(-112.5^{\circ} \mathrm{C}\right)$ and boiling $\left(6.8^{\circ} \mathrm{C}\right)$ points. ${ }^{17}$ Its structure was recently resolved showing slight deviation from linearity and alternated charges which are the primary reason for its high reactivity, having a strongly negative charged carbon at $\mathrm{C}^{2}$ surrounded by two positively charged carbon atoms $\left(\mathrm{C}^{1}\right.$ and $\left.\mathrm{C}^{3}\right) \cdot{ }^{17-18}$ Besides the interest in organic synthesis, carbon suboxide attracted attention also in polymer science, since the molecule readily polymerizes into poly(carbonsuboxide) or "Red Carbon" for its dark, wine red appearance. ${ }^{18}$ The polymer structure has been investigated, however, only few reports are available on this matter. At room temperature, the exothermic polymerization $\left(-136 \mathrm{~kJ} \mathrm{~mol}^{-1}\right)$ yields a product $\left(\mathrm{C}_{3} \mathrm{O}_{2}\right)_{\mathrm{n}}$ of well-defined stoichiometry, that when heated, releases carbon monoxide and dioxide leaving a graphite-like carbon with low oxygen content. ${ }^{17,19}$ Over the last century, many different structures have been suggested, from a spyrocyclobutadione, to poly- $\alpha$ and - $\mathrm{-}$-pyrone and cyclopolycarbonsuboxide. ${ }^{17-18,20-21}$ Often forgotten in previous reports are the biological and biochemical roles and investigations of red carbon, addressed especially by Kerek et al., at the beginning of the 2000s. In these reports, they studied natural sodium and potassium pump inhibiting factors from plant and bacterial sources and found out that natural macroring derivatives of carbon suboxide may have a primary role for efficacious therapeutic approaches against autoimmune, cardiovascular and metabolic diseases. ${ }^{22-24}$ These biological macrorings constituted of 6 to 12 units were in equilibrium between the lipophilic cyclopyrone and hydrated geminal-diol form, accompanied by significant decrease in the visible absorption, from brown to transparent. Their biological interest lies in the fact that these oligomers were found to be a strong inhibitor in rabbits and rats of the Na,K-ATPase and the sarcoplasmic endoreticulum Ca- 
ATPase. ${ }^{22,} 24$ Therefore, red carbon has a high potential interest not only in materials science, but also in biological research, as it can strongly bind metal ions.

For these reasons, herein we further investigate the synthesis of red carbon thin films prepared by means of malonic acid and phosphorus pentoxide in a test tube setup at $160^{\circ} \mathrm{C}$. In the following we will describe the synthesis and elucidate the structure, while showing also their potential use as amine optical sensors.

\section{Main}

Thin film technology is widely used in everyday objects to improve the performances of bulk materials, such as anti-corrosion and anti-wear, or self-cleaning properties, while using a very low amount of raw materials. Some examples of devices comes from our everyday life, such as LEDs, solar cells and eventually sensors. ${ }^{25-29}$ Sensors are of particular interest especially for food safety, which became recently one of the most important global issues. ${ }^{30}$ The inappropriate handling and the consumption of spoiled food causes, every year, serious problems to millions of people all over the globe. ${ }^{30} \mathrm{In}$ many cases, the presence of biogenic amines, such as putrescine or cadaverine produced by the breakdown of amino acids, indicates the microbial spoilage of the food. ${ }^{31}$ The unpleasant odor of such biogenic amines indicates a high volatility of these compounds, which are therefore detectable by chemical and/or physical sensors. ${ }^{32}$ Among the methods used for the detection of biogenic amines, such as chromatography, electrochemistry, chemiluminescence, and chemiresistance, optical methods provide a reliable and fast response with simple setups. ${ }^{33}$ It is worth mentioning that great advances have been recently made in the development of E-noses for food spoilage ,using mostly 
cross-reactive metal oxides and colorimetric sensor arrays. ${ }^{34}$ However, the use of metal oxide-based E-noses generally require high temperatures, are humidity sensitive, and cannot distinguish closely similar compounds. ${ }^{35}$

Herein, we report an unprecedent type of thin film semiconductor that can act as an optical sensor enabling to distinguish analogous amines even by naked eyes. The exposure to amines causes an irreversible change in the optical properties such as absorption and bandgap, fluorescence emission and IR spectrum. The change in photonic properties enables to use these materials not only as highly sensitive sensors, but furthermore to tune the absorption and emission of this semiconductor material, over the whole visible spectrum. Controlling the absorption/emission properties is of interest for application in photonic and optoelectronic devices.

The synthesis of red carbon thin films relies on the use of a test tube, containing a solid mixture of the precursors, malonic acid (MA) and phosphorus pentoxide $\left(\mathrm{P}_{2} \mathrm{O}_{5}\right)$, which is placed horizontally in a muffle furnace at $160^{\circ} \mathrm{C}$ with a glass slide used as a target substrate. ${ }^{3}$ At this temperature, $\mathrm{P}_{2} \mathrm{O}_{5}$ is able to double-dehydrate malonic acid, creating the carbon suboxide gas, by removing the hydroxyl groups and the a-hydrogens, which are significantly more acidic in $\beta$-diketo compounds then monoketo compounds. Furthermore, as it was previously reported, pure MA, at about the operating temperature, undergoes thermal $\beta$-decarboxylation via rearrangement in a cyclic six-membered transition state to acetic acid and $\mathrm{CO}_{2}{ }^{36-38}$ After the thermal treatment, the glass substrate is successfully coated with an deep-red film, which resembles the color described in previous reports on red carbon materials. ${ }^{18,39-40}$ Surprisingly, to the best of our knowledge, the optical absorption and emission properties were reported only once by 
Yang et al. which however are considered not comparable due to the unusual low temperatures conditions used $\left(140^{\circ} \mathrm{C}\right) \cdot{ }^{39}$ In the present case, the red color is confirmed by the absorption spectrum (Fig 2), where the red carbon thin film presents an absorption maximum at $363 \mathrm{~nm}$ with a long shoulder over a wide range of the visible spectrum, and at footing to about $600 \mathrm{~nm}$. From the spectrum, we derived an optical bandgap of about $2.1 \mathrm{eV}$ using the Tauc plot method. Furthermore, the red carbon films present an intense red fluorescence at $675 \mathrm{~nm}$ (Fig 2). The films are quite homogeneous on the glass surface, as confirmed by scanning electron microscopy (SEM) (Fig 2) picture of the film surface, with a roughness of $1 \mathrm{~nm}$ and as evaluated by atomic force microscopy (AFM) (SI). Furthermore, the material presents relatively high thermal stability, up to $200^{\circ} \mathrm{C}$ in $\mathrm{N}_{2}$, and a constant residue of about $21 \%$ at $1000^{\circ} \mathrm{C}(\mathrm{SI})$, suggesting the possibility to exploit red carbon thin films as a platform to prepare carbon-rich, homogeneous, thin films as shown later. In order to confirm that the film is homogeneously composed of carbon and oxygen, we performed energy-dispersive X-ray spectroscopy (EDX) (Fig 2) mapping of the film surface where parts of the film were removed during the sample preparation. The analysis reveals, qualitatively, that the film is mostly composed of carbon and allegedly a low contribution of oxygen. Furthermore, the silicon EDX mapping shows that the film is homogeneous without cracks and holes, since a high intensity signal for the silicon occurs only where the film has been removed during the sample preparation. The analysis also confirms the absence of phosphorus contamination the peak of which (P-K) usually occurs at about $2 \mathrm{keV}(\mathrm{SI}) \cdot{ }^{41}$ In order to obtain preliminary information on the material structure, the red carbon films were analyzed by Fourier-transform infrared spectroscopy (FTIR) (Fig 2). The spectrum confirms the presence of carbonyl-containing 
groups, occurring at $1728 \mathrm{~cm}^{-1}$ (Fig 2) is attributed to ester-like functionalities and, at lower frequencies, a wide band attributed to aromatic ring stretches appears (SI), with a minor contribution from allene and ketene groups (doublet at 1980-2030, and $2180 \mathrm{~cm}^{-1}$, respectively).
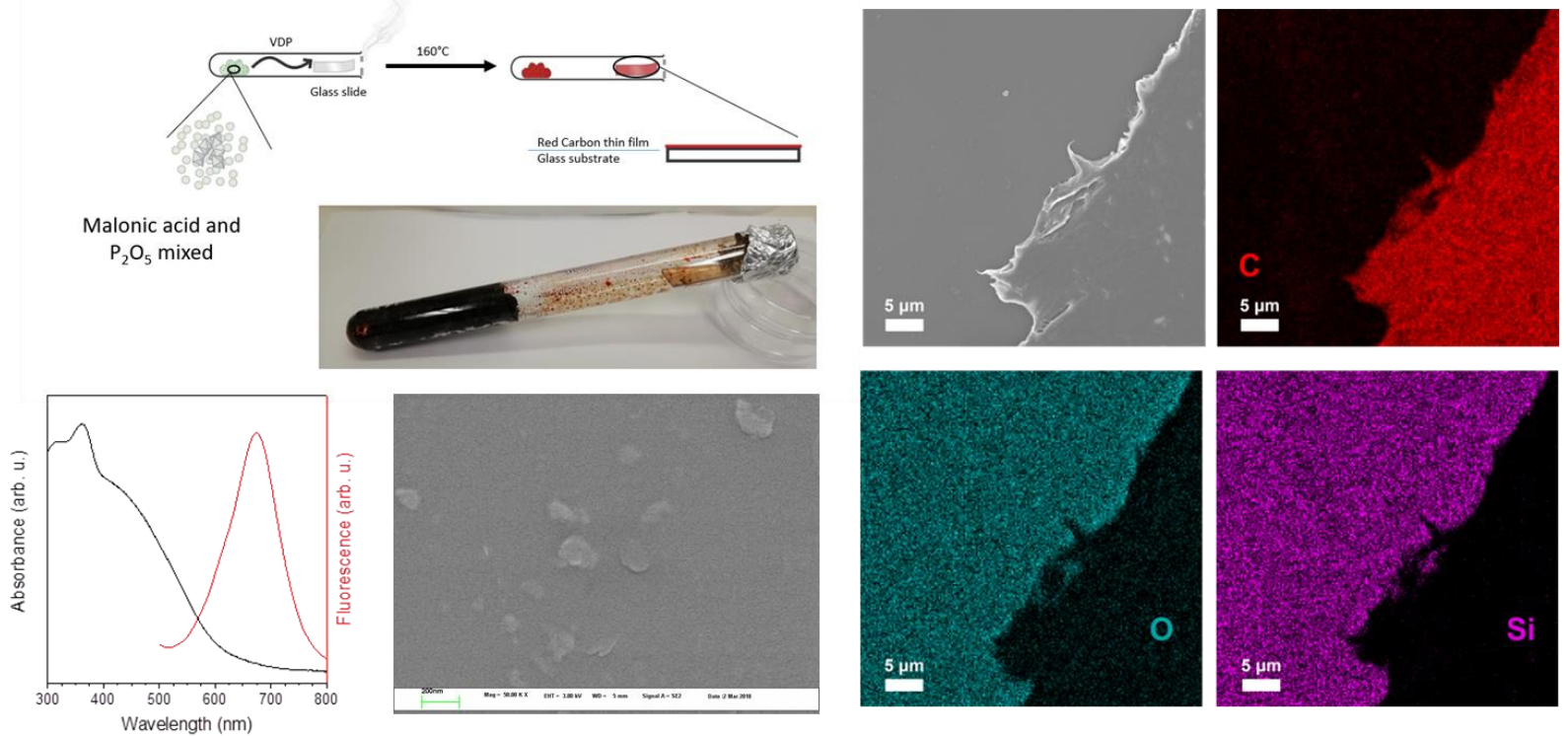

Figure 2. Synthetic method, absorbance fluorescence, SEM, EDX mapping of $\mathrm{C}, \mathrm{O}$ and Si

In order to get more insights on the chemical structure, we used a combination of X-ray diffraction (XRD), transmission electron microscopy (TEM), X-ray photoelectron spectroscopy (XPS), and electron energy loss spectroscopy (EELS) (Fig 3). The first two methods provide structural information on the material, that, in combination with XPS and EELS, enabled us to develop the chemical structure of the red carbon thin films.

The XRD results reveal a highly ordered short range structure, with seven main sharp peaks at $6.3,9.5,12.5,18.8,25.1,28.7$, and $31.6^{\circ}(2 \theta)($ Fig X). Such sharp and well 
defined peaks, which in turn reveal a very high crystalline order, are seldomly reported for organic polymer materials. Few examples of comparably high ordered structures were recently reported for poly(fantrip), polyimides, (polyaramides/oriented polyethylene/PTFE). ${ }^{42}$ At the nanoscale, the red carbon film reveal a well-organized onion-like structure with a well-defined diffraction pattern, which resembles the cyclic structure proposed by Kerek et al. ${ }^{22-24}$ Additional information, on the chemical structure are obtained by means of XPS. EELS reveals the presence of a strongly conjugated backbone, resembling the graphite pattern, although with a topological structure analogous to curved carbon materials, such as nanotube, glassy carbon, and carbon black. ${ }^{43-45}$

To provide real insights into the chemical structure, we performed XPS and deconvoluted the relative peaks, to obtain the chemical composition and relative chemical bonding scheme. It is worth noticing that also in the full spectrum XPS, we didn't find any phosphorus contamination and the elaboration of the spectra allows for defining the relative atomic composition as $\mathrm{C} / \mathrm{O}=5: 1$. The $\mathrm{C} 1 \mathrm{~s}$ spectrum shows the presence of five different bonding scheme present in the material, with a significant majority of $\mathrm{C}=\mathrm{C}$ bonds with $\mathrm{sp}^{2}$ hybridization (at $285.2 \mathrm{eV}$ ), which account for the $58.4 \%$ of the total $\mathrm{C}$ bonds. Among the $\mathrm{C}-\mathrm{C}$ bonds, also the ones with $\mathrm{sp}^{3}$ hybridization $(286.1 \mathrm{eV})$ are present, with about $21.3 \%$ relative occurrence, with a total overall of about $80 \%$ of $\mathrm{C}-\mathrm{C}$ bonds. The rest $20 \%$ is composed of $\mathrm{C}-\mathrm{O}$ bonds, with ether configuration $(10.7 \%$, at $287.4 \mathrm{eV})$, carbonyls (5.8\%, at 288.5$)$, and ester (3.8\%, at $289.7 \mathrm{eV})$. A further confirmation was obtained by synthesizing the red carbon thin films by means of fully labeled ${ }^{13} \mathrm{C}$ malonic acid 
precursor, and measured the decoupled ${ }^{13} \mathrm{C}$ spectrum (SI), which revealed the same functional groups in the material.
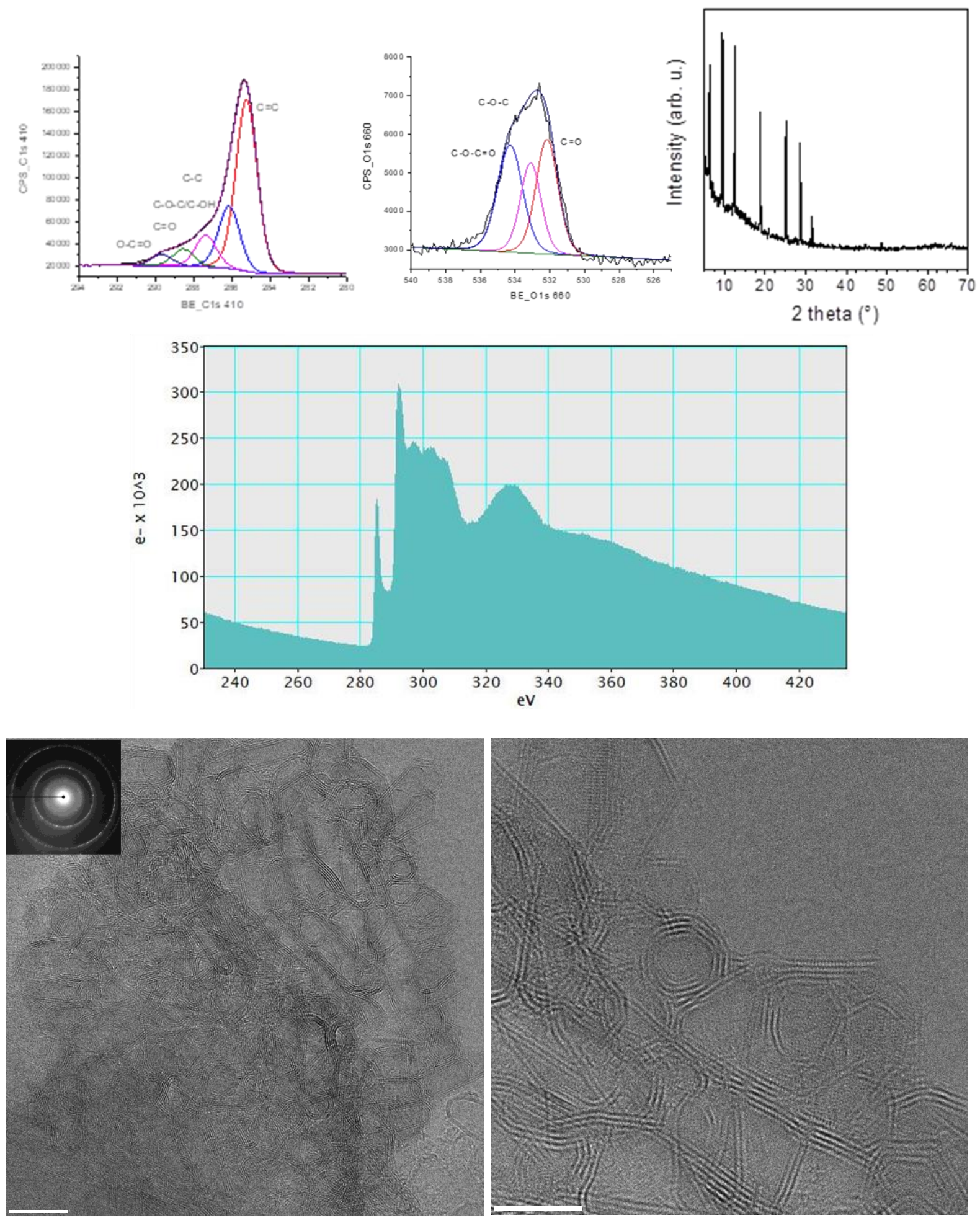
Figure 3. XPS, XRD, EELS and TEM of Red carbon.

Red carbon was reported to be highly reactive to Lewis bases, such as $\mathrm{NH}_{3}$, and, therefore, we exploited the possibility to use the red carbon thin films as sensing platform for amines. ${ }^{18,40}$ For the purpose, we chose a set of analogous alkylamines, mono-, di-, tri-ethyl and benzyl-, and an aromatic amine, aniline. In a simple setup we put $1 \mathrm{~mL}$ of the chosen amine in a $100 \mathrm{~mL}$ vessel (total volume $134 \mathrm{~mL}$ ) and immediately sealed, after placing inside a $2.5 \mathrm{~cm}^{2}$ red carbon thin film in another $5 \mathrm{ml}$ vessel, to avoid direct contact with the liquid amine, as shown in the following (fig. 4). In this way we assure that, if a reaction occurs, this happens only via gas-to-solid phase reaction. As shown in the following, the films after 24 hours exposure have a significantly different color, which can even be distinguished by naked eyes. As expected, the color change is stronger for primary amines than for higher and aromatic amines, after 24 hours; thus, the color change is not due to the higher vapor pressure of the amine, but to a chemical reaction between the red carbon films and the amine. Indeed, the boiling point of the ethylamine is $16.6^{\circ} \mathrm{C}$, whereas benzylamine (which is as well a primary amine) is $185^{\circ} \mathrm{C}$, at atmospheric pressure. A further proof of the chemical reaction is obtained by confirming the irreversibility of the color change by measuring the absorption spectrum after the exposure to ethylamine and after placing the sample in a vacuum over for 48 hours at $60^{\circ} \mathrm{C}(\mathrm{SI})$. 


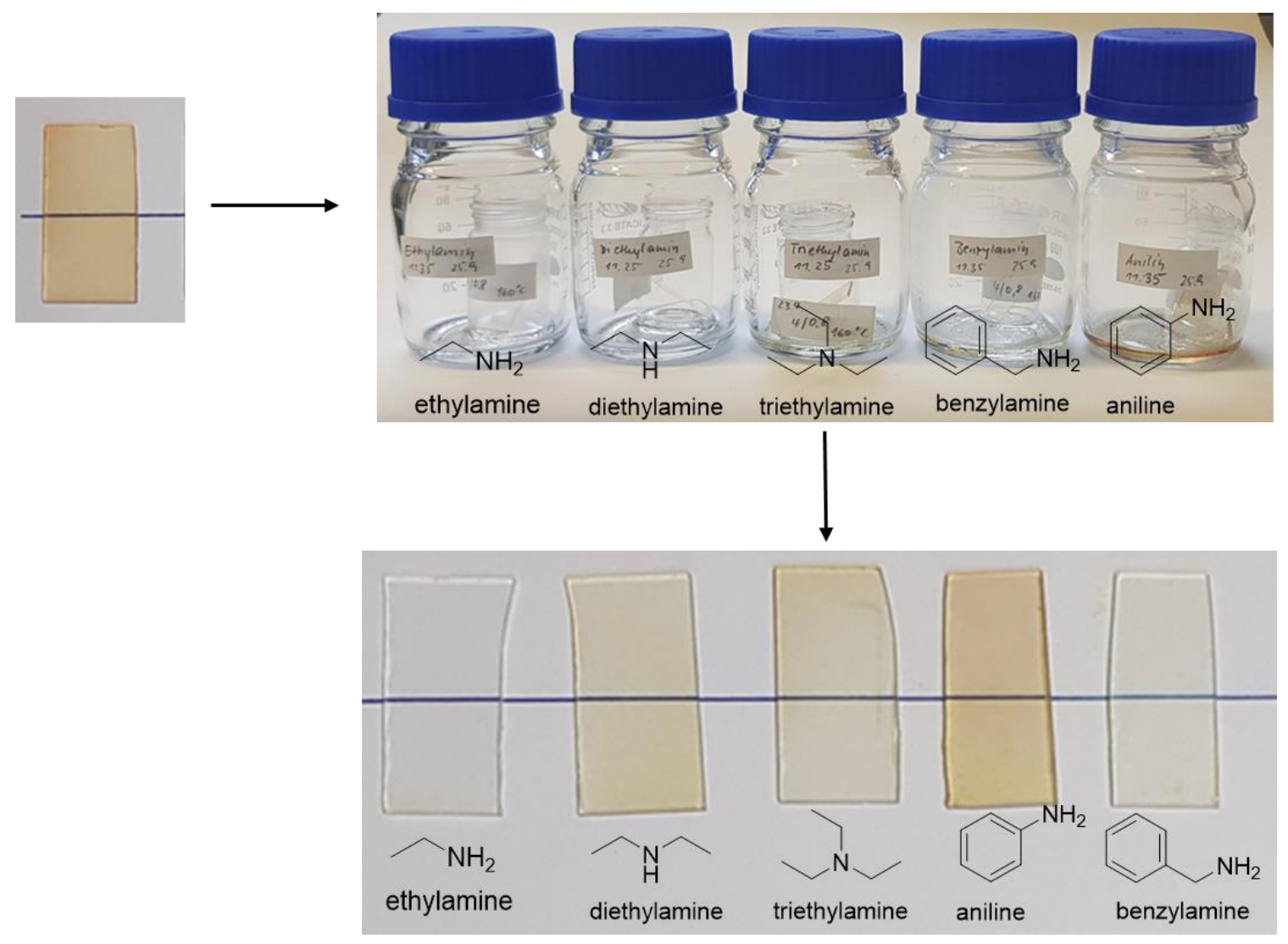

Figure 4. Sensing setup for RC films with amines

The spectral changes were recorded over time, between 30 seconds and 48 hours at arbitrarily chosen intervals (30 seconds, 5,30 minutes, 1, 4, 13, 24, 48 hours) for each chosen amine. The absorption spectra (SI) were further elaborated and extracted the bandgap values by the Tauc plot method, in order to retrieve one number as a meaningful reference point for comparing the sensing properties of the red carbon thin films. The absorption spectra elaboration shows a faster response for ethylamine, with respect to all other amines, with a strong bandgap blue-shift (from 2.10 to $2.52 \mathrm{eV}$ ) already after 30 seconds of exposure, which can be attributed to the higher vapor pressure and faster reaction kinetics of ethylamine. In all cases, after already one hour of exposure, we recorded a bandgap blue-shift, which is larger for the primary amines (2.78 eV for ethylamine, $2.61 \mathrm{eV}$ for benzylamine) and the lowest for aniline $(2.3 \mathrm{eV})$. This is possibly 
due to the higher $\mathrm{pK}_{\mathrm{a}}$ value (4.6), which speaks for different orders of magnitude higher acidity compared to the the other amines used here, and with comparable boiling point to benzylamine. In this way, we can rule out the predominant effect of the vapor pressure on the response, when vapor pressure equilibrium condition is reached. This is confirmed, by looking at the points after 24 and 48 hours of exposure. Indeed, ethylamine enables a very large bandgap blue shift of $1.14 \mathrm{eV}$ (from 2.10 of bare red carbon to $3.24 \mathrm{eV}$ after 48 hours) and 0.87 for benzylamine (2.97 eV after 48 hours). Concerning the other amines, the bandgap widening is similar after 48 hours, with a maximum total blue shift of about 0.4 to $0.5 \mathrm{eV}$. However, the shape of the sensing curve (Fig 5) reveal a different kinetics, and behavior for each different amine, which would enable to distinguish them in a simple manner, particularly efficient for primary vs. secondary/tertiary and aromatic ones. Besides the possibility to distinguish different analogous amines, with similar chemicophysical properties, the methods reveal a technique to tune the optical properties of this material over almost the whole visible spectrum. Eventually, one can expect, that other compounds would enable a different blue- (or red-) shift of the optical properties, as well as, an irreversible incorporation in the material of the chosen element, such as boron, sulfur and so forth, making this material a very interesting platform for vapor sensing.

As previously mentioned, red carbon thin films possess a strong fluorescence in the red range of the spectrum $(675 \mathrm{~nm})$. Therefore, another very attractive opportunity is the change in the photoluminescence for sensing. As expected, photoluminescence also blue-shifts, more for ethylamine and benzylamine than for other amines. In the first case, after 48 hours of exposure, causes a shift of the photoluminescence from $675 \mathrm{~nm}$ of the bare red carbon down to the near UV range $(384 \mathrm{~nm})(\mathrm{SI})$. In the second one, 
benzylamine, fluorescence shifts in the cyan region, with a maximum at $499 \mathrm{~nm}$. The blue-shift is however, less strong for diethylamine, trimethylamine and aniline, analogously to the absorption spectrum, shifting to the orange spectral range $(\approx 595-610$ $n m)$. It is worth noticing, that in this way the red carbon thin films and its amino-sensed derivatives enable covering almost the full color spectral range, from the red, through yellow, green, and cyan, down to the deep blue and even near-UV spectrum, blue-shifting more for longer exposure times (to amine vapors) and for primary amines, as exemplarily shown by the CIE 1931 graph (Fig 5). Such a wide range of bandgap size and photoluminescence tunability in a simple manner as such gained a lot of attention recently for application in optoelectronics, optical sensors, bioimaging with other materials. ${ }^{46-47}$ Therefore, we assume that the herein presented red carbon thin films can take a share in the above applications, especially for their simple synthetic method as well as their easy tunability over a wide spectral range.

Last but not least, the sensing kinetics can be followed also by FTIR. Indeed, the strong absorption of the carbonyl group, shifts towards lower wavenumbers, confirming that a reaction occurs between the ester group $\left(1730 \mathrm{~cm}^{-1}\right)$ that is possibly converted into an amide $\left(1650 \mathrm{~cm}^{-1}\right)$ for ethylamine already after 30 seconds. Therefore, we were keen on figuring out what happens to the red carbon films after exposure, and we exploited as a model sample ethylamine after 24 hours of exposure. The surface morphology, evaluated by SEM, reveals that the exposure to ethylamine vapors causes the formation of some dot-like surface defects attributed to the chemical reaction, and by means of EDX we could prove further that the $\mathrm{N}$ is successfully incorporated into the thin film material (SI maybe). In terms of thermal stability, at lower temperature the material is stable up to 
$160^{\circ} \mathrm{C}$, a bit lower than the bare red carbon film with, however, a larger leftover product at $1000^{\circ} \mathrm{C}(25.5 \%$ in nitrogen atmosphere $) .{ }^{1}$ Once more, XPS can provide further insights in the materials structure, after modification with ethylamine vapors for 24 hours. In good agreement with what already expected by FTIR, the reaction with ethylamine leads to the formation of amide bonds (287.8, 400.4, and $533.1 \mathrm{eV}$ ) accompanied by a significant reduction of the ester bond signal (fig 5). Furthermore, a deconvoluted peak attributed to $-\mathrm{NH}$ groups, appearing also in the FTIR spectrum (SI), shows that the reaction goes via pyrone ring-opening which would eventually close with elimination of water to pyridinone, as schematically shown in figure 5 . Therefore, the intermediate ring-opening would explain the blue-shift in absorbance and fluorescence, since the main product (the intermediate) has a reduced conjugation length. We can assume that the intermediate is the major reaction product, because of the intense $-\mathrm{NH}$ signal in XPS and FTIR. Additionally, XPS enables to derive the relative elemental composition as $\mathrm{C}_{15} \mathrm{NO}_{2}$ (C $83.6 \%, \mathrm{O} 11.0 \%$, and $\mathrm{N} 5.4 \%$ ) confirming thus the partial substitution of oxygen with nitrogen $\left(\mathrm{C} / \mathrm{O}=5.1 \approx \mathrm{C}_{5} \mathrm{O}=\mathrm{C}_{15} \mathrm{O}_{3} ; \mathrm{C}_{15} \mathrm{O}_{3}-1^{*} \mathrm{O}+1^{*} \mathrm{~N}=\mathrm{C}_{15} \mathrm{NO}_{2}\right)$, by means of the ethylamine vapor. 

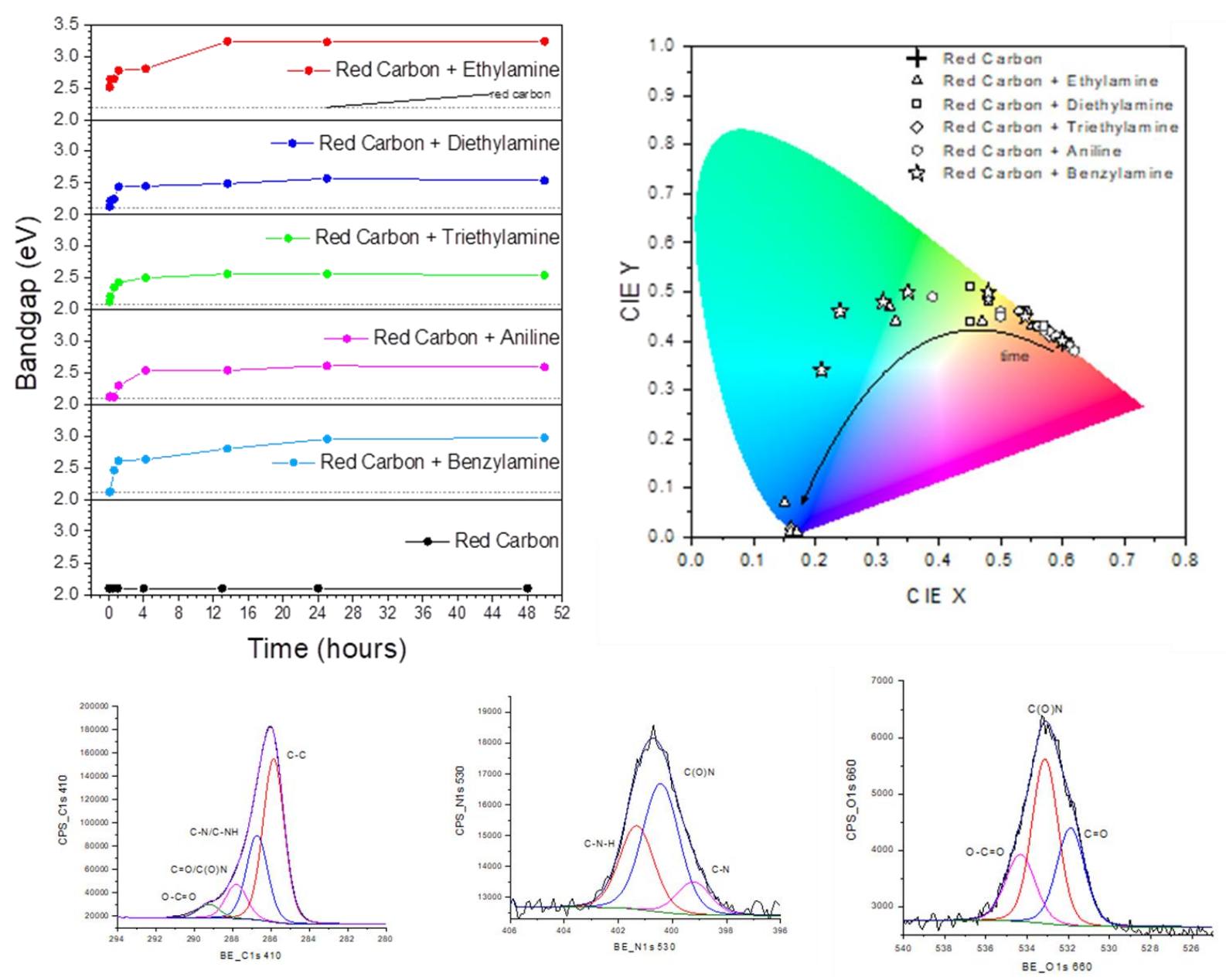<smiles>CCNC(=O)/C=C\C=C(/C)C(=O)NCC</smiles><smiles>CCn1ccccc1=O</smiles> 
Figure 5. Bandgap shift, fluorescence shift for RC exposed to selected amines. XPS of red carbon exposed to ethylamine for 24 hours. Proposed simplified mechanism for the reaction of RC with ethylamine.

TGA profile of the bare red carbon and after exposure to ethylamine for 24 hours, reveal the possibility to prepare carbon materials as thin films, with the possibility to selectively introduce nitrogen functionalities. Indeed, as shown in the following (fig 6), SEM and EDX confirm that the film is still present after treatment at $400^{\circ} \mathrm{C}$, with some surface defects occurring due to the thermal process (SI?!!). The presence of the thin film on the glass surface can be confirmed though where a scratch was done with the tweezers and the film partially is removed $(\mathrm{SI})$. Furthermore, EDX once more confirms the presence of $\mathrm{C}$, O, and, for the sample exposed to ethylamine, $\mathrm{N}$.

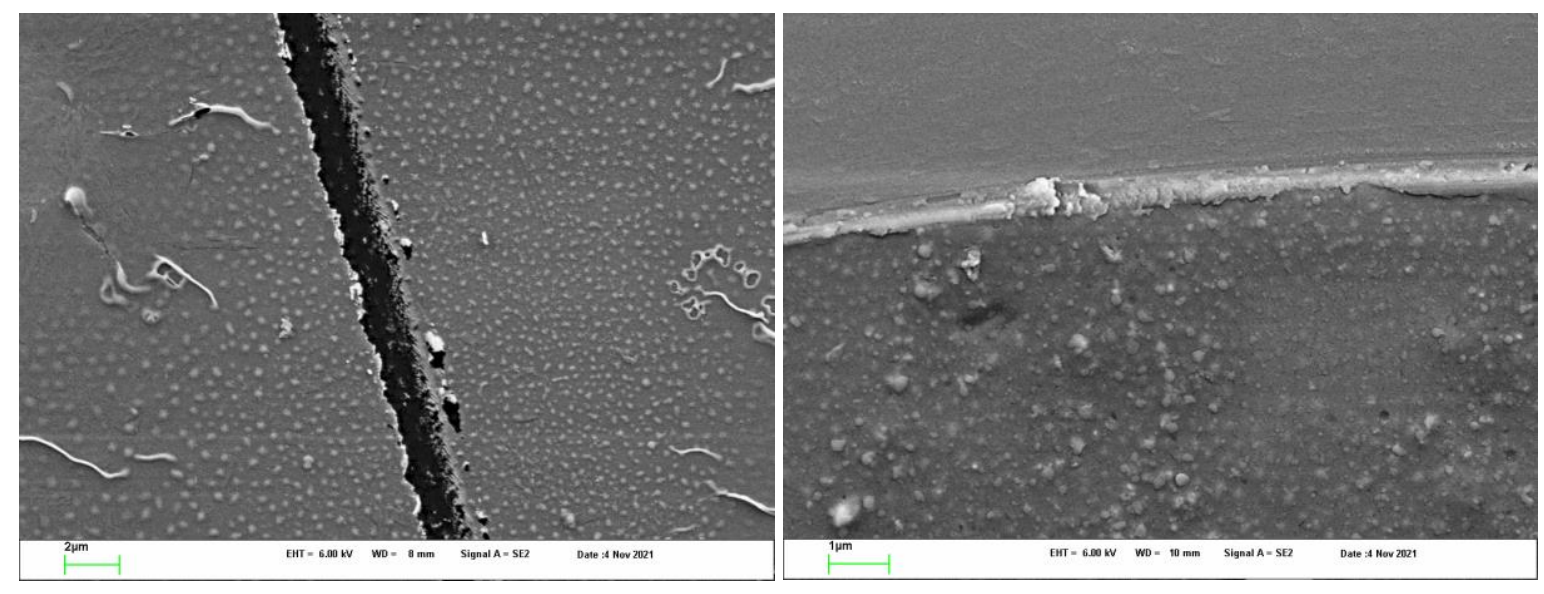

Figure $6 \mathrm{SEM}$ of $\mathrm{RC}$ and $\mathrm{RC}+\mathrm{etnh} 2$ at $400^{\circ} \mathrm{C}$.

These products were further analyzed via absorbance, FTIR, and XPS. The absorbance spectra show an increased optical absorption in the visible range for the bare $\mathrm{RC}$ film further condensed at $400{ }^{\circ} \mathrm{C}$, whereas a high transparency for the one exposed to ethylamine was preserved. FITR shows, as expected, a quite low absorption for both 
samples, in the range $4000-1300 \mathrm{~cm}^{-1}$. In both samples, however, three features can be easily distinguished and attributed to $\mathrm{C}=\mathrm{C}$ bonds $\left(1600 \mathrm{~cm}^{-1}\right)$, condensed allene bonds that appears as a doublet at about 1970 and $2015 \mathrm{~cm}^{-1}$, and ketene units at $2179 \mathrm{~cm}^{-1}$ (Figure 7$) .48$
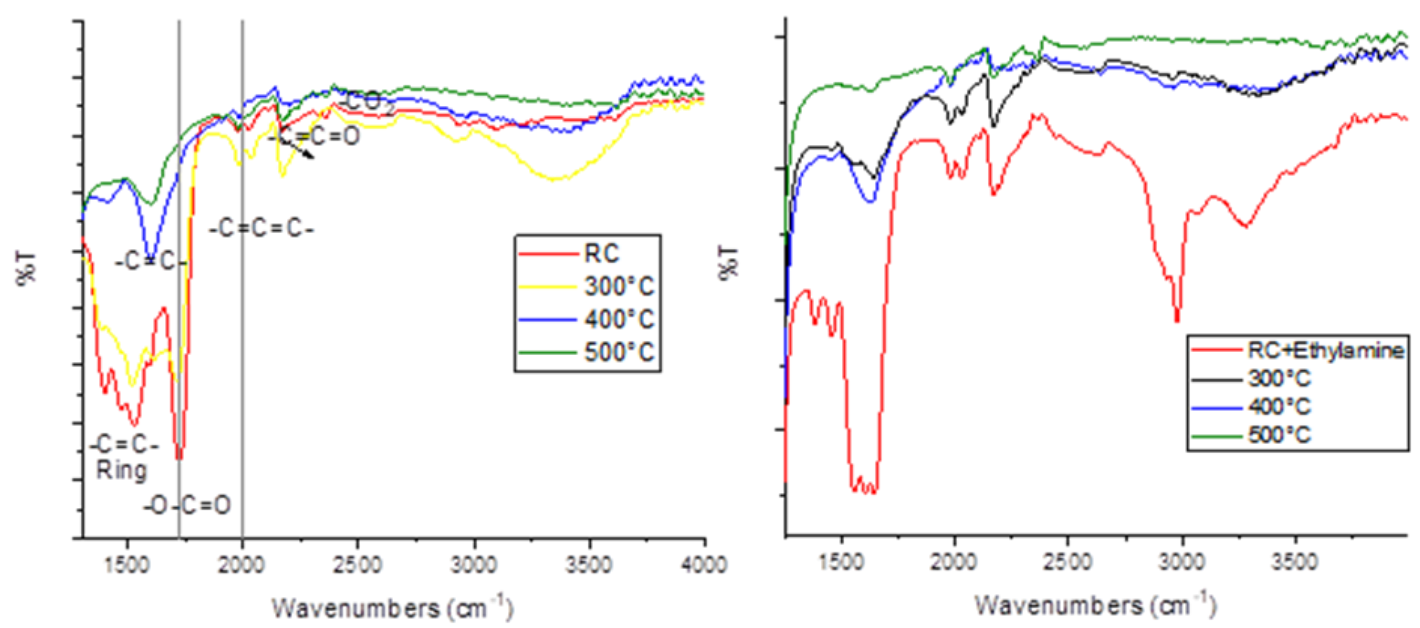

Figure 7. FTIR of the RC and RC exposed to ethylamine after thermal treatment

In order to get further insights in the films, XPS spectra were collected. The spectra confirm that at $500^{\circ} \mathrm{C}$, the samples are still present, and up to $400^{\circ} \mathrm{C}$ part of the nitrogen remains in the structure. The operando XPS spectra clearly show that the thermal treatment modifies the chemical environment of the $\mathrm{RC}$ thin film while heating (Fig 8). The major sp² C-C peak shifts to lower binding energies, from $285.0 \mathrm{eV}$ to $284.4 \mathrm{eV}$, which therefore speaks for significantly more electron rich $\mathrm{C}-\mathrm{C}$ bonding scheme. The more oxidized peaks, significantly reduce in intensity and remain as a tail up to $500^{\circ} \mathrm{C}$. Analogously, The O1s spectra recorded at different temperatures reveal the appearance of the $\mathrm{SnO}$ (ca. $531 \mathrm{eV}$ ) attributed to a thinning and eventually cracks of the film occurring during the carbonization. However, the peak attributed to carbonyl carbon is still present at $532.1 \mathrm{eV}$ even at $500^{\circ} \mathrm{C}$, with a final $\mathrm{C} / \mathrm{O}$ ratio of about $42(97.67 \% \mathrm{C}, 2.33 \% \mathrm{O})$. The 
increased condensation and the successful carbonization of the film is confirmed also by the picture of the sample at $500^{\circ} \mathrm{C}$, where the color turns darker and the absorption increases accordingly in the whole visible spectrum (SI), speaking for a higher conjugation achieved in the sample. To evaluate the possibility of creating $\mathrm{N}$-doped carbon thin films by this method we performed analogous experiment for the RC sample exposed to ethylamine for 24 hours. Analogously to the case of the RC film, a major change in the $\mathrm{C} 1 \mathrm{~s}$ spectrum appears at $300^{\circ} \mathrm{C}$, where the main peak progressively shifts from $285.5 \mathrm{eV}$ (at room temperature) to lower binding energies $\left(284.7 \mathrm{eV}\right.$ at $300^{\circ} \mathrm{C}$ ) reaching $284.4 \mathrm{eV}$ at $500^{\circ} \mathrm{C}$, with the other peaks fading in a low intensity tail. Analogously to the case of the $\mathrm{RC}$ film the O1s peak reveals similar behavior, with the appearance of the peak attributed to the $\mathrm{SnO}$ substrate, due to thinning and cracks formation during the carbonization. When raising the temperature, the N1s peak is present and clearly detectable until $400^{\circ} \mathrm{C}$, whereas at $500^{\circ} \mathrm{C}$ cannot be detected anymore. The thermal treatment induces also for the nitrogen a major change between $200^{\circ} \mathrm{C}$ and $300^{\circ} \mathrm{C}$, with the appearance of a feature at lower binding energies $(398.2 \mathrm{eV})$ together with the amide bond at $400.4 \mathrm{eV}$. The $398.2 \mathrm{eV}$ feature was previously attributed to pyridinic nitrogen, therefore, confirming the possibility to successfully introduce nitrogen within the material structure.$^{57}$ It is worth pointing out that in this case the material obtained at $400^{\circ} \mathrm{C}$ has a high transparency in the visible range as confirmed by the sample picture and absorbance spectrum (SI), with a higher conjugation degree including pyridinic and amide functional groups. This is supported also by the low absorption in the NIR spectrum (supporting info), typical of carbon materials which show a major peak appearing at $1620 \mathrm{~cm}^{-1}$, attributed to the $\mathrm{C}=\mathrm{C}$ stretching, in good agreement with XPS results (the absorption at 
wavenumbers below $1500 \mathrm{~cm}-1$ is due to the glassy substrate). Furthermore, we could define the CNO composition (excluding the oxygen attributed to the substrate) as ca. $\mathrm{C}_{27} \mathrm{NO}(92.82 \% \mathrm{C}, 3.39 \% \mathrm{~N}, 3.79 \% \mathrm{O})$ (Fig 8). Hence, the composition confirms the large majority of carbon, in a conjugated scheme, with about $3 \%$ and $4 \%$ of $\mathrm{N}$ and $\mathrm{O}$, respectively. However, when increasing the temperature to $500^{\circ} \mathrm{C}$, the nitrogen peak cannot be detected anymore, and the leftover film is composed by carbon and oxygen with a $\mathrm{C} / \mathrm{O}$ ratio of $9.9(90.8 \% \mathrm{C}, 9.2 \% \mathrm{O})$, much lower than the bare $\mathrm{RC}$ film. The significant difference in the oxygen content can be a reason for the significantly different optical properties $(\mathrm{SI})$, though with still a very high carbon content. The relative elemental composition study at different temperatures reveal the possibility to control tightly the elemental composition in the material and, therefore, the properties. In good agreement with the TGA, until 100 degree the sample does not change, the composition remains the same (Fig 8). Minor changes occur at $200-300^{\circ} \mathrm{C}$ and, very interestingly, we see a different behavior between the 2 samples: in the $\mathrm{RC}$ film, the $\mathrm{C} \%$ increases where the oxygen decreases, whereas in the $\mathrm{RC}+$ ethylamine, $\mathrm{N} \%$ increases at the expenses of oxygen and nitrogen. At $400^{\circ} \mathrm{C}$ the carbon content increases significantly for both samples reducing the heteroatoms content, with minor changes at $500^{\circ} \mathrm{C}$ for $\mathrm{RC}$. In the case of $\mathrm{RC}+$ ethylamine, the step between 400 and $500^{\circ} \mathrm{C}$ causes the complete removal of the nitrogen accompanied by an increase of 1.6 -fold of oxygen content. This suggest therefore that at these temperatures the main thermal decomposition proceeds via removing $\mathrm{C}-\mathrm{N}$ fragments. Eventually we expect that by using other gaseous doping agents, instead of ethylamine, the doping can be further kept in even at higher temperatures. The doping scheme and the study via XPS would help to depict the type 
of bond formed via the gaseous doping agent and therefore design thin films with the desired properties and chemical composition.
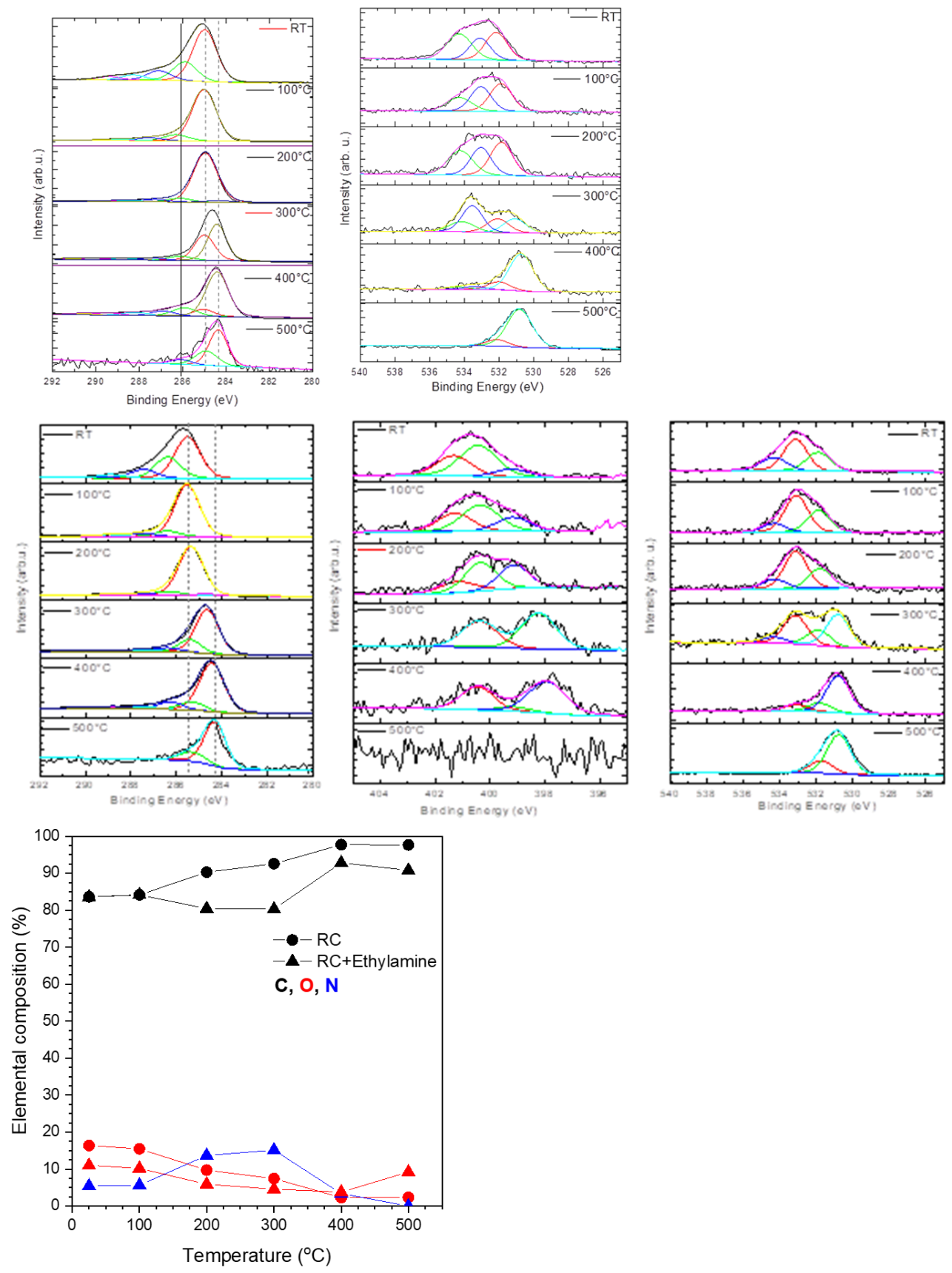

Figure 8. Operando XPS of RC and RC+ ethylamine. Relative chemical composition at different $\mathrm{T}$. 


\section{Conclusion}

Red carbon thin films were synthesized in a simple test tube approach by acid catalyzed decomposition of malonic acid. Sample analysis was performed using a combination of spectroscopic and microscopic techniques revealing a highly organized structure.

Furthermore, the red carbon thin films have been exploited as a platform for amine sensing which have revealed the possibility to distinguish similar amines, such as primary secondary, tertiary and aromatics. The wide change in absorption, emission and FTIR spectra makes the red carbon films a convenient sensing platform for amines.

As we proved that the sensing properties occurs in an irreversible manner via chemical reaction, the films were also exploited to prepare $\mathrm{N}$-doped carbon thin films, by simple post-carbonization at $400-500{ }^{\circ} \mathrm{C}$ directly at the substrate surface. This would enable on the one hand to prepare carbon thin films at low temperature and directly at the substrate surface, and, on the other hand, to introduce nitrogen in the structure in a simple manner, for the development of thin film carbon devices, such as resistive sensors, thin film catalysts, capacitors and beyond. We believe that the materials and the approaches used in this work will open the way for a new exciting and wide utilization of carbon and heteroatom doped carbon materials as thin films, with a functional and easily tunable platform for wide range of applications.

\section{Bibliography}

1. Antonietti, M.; Oschatz, M., The Concept of "Noble, Heteroatom-Doped Carbons," Their Directed Synthesis by Electronic Band Control of Carbonization, and Applications in Catalysis and Energy Materials. Advanced Materials 2018, 30 (21), 1706836.

2. Walczak, R.; Kurpil, B.; Savateev, A.; Heil, T.; Schmidt, J.; Qin, Q.; Antonietti, M.; Oschatz, M., Template-and Metal-Free Synthesis of Nitrogen-Rich Nanoporous "Noble" Carbon Materials by Direct 
Pyrolysis of a Preorganized Hexaazatriphenylene Precursor. Angewandte Chemie International Edition 2018, 57 (33), 10765-10770.

3. Giusto, P.; Arazoe, H.; Cruz, D.; Lova, P.; Heil, T.; Aida, T.; Antonietti, M., Boron Carbon Nitride Thin Films: From Disordered to Ordered Conjugated Ternary Materials. Journal of the American Chemical Society 2020.

4. Sakaushi, K.; Antonietti, M., Carbon- and Nitrogen-Based Organic Frameworks. Accounts of Chemical Research 2015, 48 (6), 1591-1600.

5. $\quad$ Fechler, N.; Zussblatt, N. P.; Rothe, R.; Schlögl, R.; Willinger, M. G.; Chmelka, B. F.; Antonietti, M., Eutectic syntheses of graphitic carbon with high pyrazinic nitrogen content. Advanced Materials 2016, 28 (6), 1287-1294.

6. Thomas, A.; Fischer, A.; Goettmann, F.; Antonietti, M.; Müller, J.-O.; Schlögl, R.; Carlsson, J. M., Graphitic carbon nitride materials: variation of structure and morphology and their use as metal-free catalysts. Journal of Materials Chemistry 2008, 18 (41), 4893-4908.

7. Giusto, P.; Cruz, D.; Heil, T.; Arazoe, H.; Lova, P.; Aida, T.; Comoretto, D.; Patrini, M.; Antonietti, M., Shine Bright Like a Diamond: New Light on an Old Polymeric Semiconductor. Adv Mater 2020, 32 (10), 1908140.

8. Savateev, A.; Ghosh, I.; König, B.; Antonietti, M., Photoredox catalytic organic transformations using heterogeneous carbon nitrides. Angewandte Chemie International Edition 2018, 57 (49), 1593615947.

9. Giusto, P.; Cruz, D.; Heil, T.; Tarakina, N.; Patrini, M.; Antonietti, M., Chemical Vapor Deposition of Highly Conjugated, Transparent Boron Carbon Nitride Thin Films. Advanced Science 2021, n/a (n/a), 2101602.

10. Wang, X.; Maeda, K.; Thomas, A.; Takanabe, K.; Xin, G.; Carlsson, J. M.; Domen, K.; Antonietti, M., A metal-free polymeric photocatalyst for hydrogen production from water under visible light. Nature materials 2009, 8 (1), 76.

11. Travlou, N. A.; Seredych, M.; Rodríguez-Castellón, E.; Bandosz, T. J., Insight into ammonia sensing on heterogeneous S-and N-co-doped nanoporous carbons. Carbon 2016, 96, 1014-1021.

12. Dashkevich, L. B.; Beilin, V., Carbon suboxide in organic synthesis. Russian Chemical Reviews 1967, 36 (6), 391.

13. Kappe, T.; Ziegler, E., Carbon Suboxide in Preparative Organic Chemistry. New synthetic methods (1). Angewandte Chemie International Edition in English 1974, 13 (8), 491-504.

14. Brodie, B. C., II. Note on the synthesis of marsh-gas and formic acid, and on the electric decomposition of carbonic oxide. Proceedings of the Royal Society of London 1873, 21 (139-147), 245-247.

15. Reyerson, L.; Kobe, K., Carbon Suboxide. Chemical Reviews 1930, 7 (4), 479-492.

16. Giusto, P. Chemical vapor deposition of carbon-based thin films. Universität Potsdam, 2020.

17. auf der Günne, J. S.; Beck, J.; Hoffbauer, W.; Krieger-Beck, P., The structure of poly (carbonsuboxide) on the atomic scale: a solid-state NMR study. Chem. Eur. J 2005, 11 (15), 4429-4440.

18. Carofiglio, T.; Pandolfo, L.; Paiaro, G., Carbon suboxide polymers. European polymer journal 1986, 22 (6), 491-497.

19. Kybett, B.; Johnson, G.; Barker, C.; Margrave, J., The heats of formation and polymerization of carbon suboxide. The Journal of Physical Chemistry 1965, 69 (10), 3603-3606.

20. Diels, O.; Meyerheim, G., Über das Kohlensuboxyd (II). Berichte der deutschen chemischen Gesellschaft 1907, 40 (1), 355-363.

21. Ziegler, E. In UBER DIE KONSTITUTIONELLEN BEZIEHUNGEN ZWISCHEN POLYPYRONOVERBINDUNGEN UND DER ROTEN KOHLE, ANGEWANDTE CHEMIE-INTERNATIONAL EDITION, WILEY-V CH VERLAG GMBH MUHLENSTRASSE 33-34, D-13187 BERLIN, GERMANY: 1960; pp 582-582.

22. Kerek, F., The structure of the digitalislike and natriuretic factors identified as macrocyclic derivatives of the inorganic carbon suboxide. Hypertension Research 2000, 23 (Supplement), S33-S38. 
23. Stimac, R.; Kerek, F.; APELL, H. J., Macrocyclic Carbon Suboxide Oligomers as Potent Inhibitors of the Na, K-ATPase. Annals of the New York Academy of Sciences 2003, 986 (1), 327-329.

24. Kerek, F.; Stimac, R.; Apell, H.-J.; Freudenmann, F.; Moroder, L., Characterization of the macrocyclic carbon suboxide factors as potent $\mathrm{Na}, \mathrm{K}-\mathrm{ATP}$ ase and SR Ca-ATPase inhibitors. Biochimica et Biophysica Acta (BBA)-Biomembranes 2002, 1567, 213-220.

25. Paola Lova, P. G., Francesco Di Stasio, Giovanni Manfredi, Giuseppe Maria Paterno, Daniele Cortecchia, Cesare Soci; Comoretto, D., All-polymer methylammonium lead iodide perovskite microcavity. Nanoscale 2019.

26. Fu, X.; Mehta, Y.; Chen, Y.-A.; Lei, L.; Zhu, L.; Barange, N.; Dong, Q.; Yin, S.; Mendes, J.; He, S.; Gogusetti, R.; Chang, C.-H.; So, F., Directional Polarized Light Emission from Thin-Film Light-Emitting Diodes. Advanced Materials 2021, 33 (9), 2006801.

27. Roesch, R.; Faber, T.; Von Hauff, E.; Brown, T. M.; Lira-Cantu, M.; Hoppe, H., Procedures and Practices for Evaluating Thin-Film Solar Cell Stability. Advanced Energy Materials 2015, 5 (20), 1501407.

28. Lee, T. D.; Ebong, A. U., A review of thin film solar cell technologies and challenges. Renewable and Sustainable Energy Reviews 2017, 70, 1286-1297.

29. Megahd, H.; Lova, P.; Comoretto, D., Universal Design Rules for Flory-Huggins Polymer Photonic Vapor Sensors. Advanced Functional Materials 2021, 31 (9), 2009626.

30. Wang, J.; Li, D.; Ye, Y.; Qiu, Y.; Liu, J.; Huang, L.; Liang, B.; Chen, B., A Fluorescent Metal-Organic Framework for Food Real-Time Visual Monitoring. Advanced Materials 2021, 33 (15), 2008020.

31. Megahd, H.; Oldani, C.; Radice, S.; Lanfranchi, A.; Patrini, M.; Lova, P.; Comoretto, D., AquivionPoly(N-vinylcarbazole) Holistic Flory-Huggins Photonic Vapor Sensors. Advanced Optical Materials 2021, 9 (5), 2002006.

32. Ma, Z.; Chen, P.; Cheng, W.; Yan, K.; Pan, L.; Shi, Y.; Yu, G., Highly Sensitive, Printable Nanostructured Conductive Polymer Wireless Sensor for Food Spoilage Detection. Nano Letters 2018, 18 (7), 4570-4575.

33. Lova, P.; Manfredi, G.; Comoretto, D., Advances in Functional Solution Processed Planar 1D Photonic Crystals. Advanced Optical Materials 2018, 6 (24), 1800730.

34. Guo, L.; Wang, T.; Wu, Z.; Wang, J.; Wang, M.; Cui, Z.; Ji, S.; Cai, J.; Xu, C.; Chen, X., Portable FoodFreshness Prediction Platform Based on Colorimetric Barcode Combinatorics and Deep Convolutional Neural Networks. Advanced Materials 2020, 32 (45), 2004805.

35. Li, Z.; Askim, J. R.; Suslick, K. S., The Optoelectronic Nose: Colorimetric and Fluorometric Sensor Arrays. Chemical Reviews 2019, 119 (1), 231-292.

36. Sutton, C. C. R.; Lim, C.-Y.; da Silva, G., Self-catalyzed keto-enol tautomerization of malonic acid. International Journal of Quantum Chemistry 2020, 120 (5), e26114.

37. Pollack, R. M., Decarboxylations of $\beta$-keto acids and related compounds. In Transition States of Biochemical Processes, Springer: 1978; pp 467-492.

38. Hinshelwood, C. N., XX.-The rate of decomposition of malonic acid. Journal of the Chemical Society, Transactions 1920, 117, 156-165.

39. Yang, N. L.; Snow, A.; Haubenstock, H.; Bramwell, F., Poly (carbon suboxide): a photosensitive paramagnetic ladder polymer. Journal of Polymer Science: Polymer Chemistry Edition 1978, 16 (8), 19091927.

40. Snow, A.; Haubenstock, H.; Yang, N.-L., Poly (carbon suboxide). Characterization, polymerization, and radical structure. Macromolecules 1978, 11 (1), 77-86.

41. Karki, B.; Rajapakse, M.; Sumanasekera, G. U.; Jasinski, J. B., Structural and thermoelectric properties of black arsenic-phosphorus. ACS Applied Energy Materials 2020, 3 (9), 8543-8551.

42. Kissel, P.; Murray, D. J.; Wulftange, W. J.; Catalano, V. J.; King, B. T., A nanoporous twodimensional polymer by single-crystal-to-single-crystal photopolymerization. Nature chemistry 2014, 6 (9), 774-778. 
43. El-Barbary, A.; Trasobares, S.; Ewels, C.; Stephan, O.; Okotrub, A.; Bulusheva, L.; Fall, C.; Heggie, M. In Electron spectroscopy of carbon materials: experiment and theory, Journal of Physics: Conference Series, IOP Publishing: 2006; $\mathrm{p} 035$.

44. Jurkiewicz, K.; Pawlyta, M.; Burian, A., Structure of Carbon Materials Explored by Local Transmission Electron Microscopy and Global Powder Diffraction Probes. C 2018, 4 (4), 68.

45. Cruz-Rosas, H. I.; Riquelme, F.; Santiago, P.; Rendón, L.; Buhse, T.; Ortega-Gutiérrez, F.; BorjaUrby, R.; Mendoza, D.; Gaona, C.; Miramontes, P., Multiwall and bamboo-like carbon nanotubes from the Allende chondrite: A probable source of asymmetry. Plos one 2019, 14 (7), e0218750.

46. Sutherland, B. R.; Sargent, E. H., Perovskite photonic sources. Nature Photonics 2016, 10 (5), 295 302.

47. Wei, S.; Li, Z.; Lu, W.; Liu, H.; Zhang, J.; Chen, T.; Tang, B. Z., Multicolor Fluorescent Polymeric Hydrogels. Angewandte Chemie International Edition 2021, 60 (16), 8608-8624.

48. Standards, N. I. o.; Technology, NIST Chemistry WebBook, SRD 69. 2018.

49. Brandi, F.; Bäumel, M.; Molinari, V.; Shekova, I.; Lauermann, I.; Heil, T.; Antonietti, M.; Al-Naji, M., Nickel on nitrogen-doped carbon pellets for continuous-flow hydrogenation of biomass-derived compounds in water. Green Chemistry 2020, 22 (9), 2755-2766.

50. Travlou, N. A.; Ushay, C.; Seredych, M.; Rodríguez-Castellón, E.; Bandosz, T. J. J. A. S., Nitrogendoped activated carbon-based ammonia sensors: effect of specific surface functional groups on carbon electronic properties. 2016, 1 (5), 591-599.

51. Zheng, Y.; Jiao, Y.; Zhu, Y.; Li, L. H.; Han, Y.; Chen, Y.; Du, A.; Jaroniec, M.; Qiao, S. Z., Hydrogen evolution by a metal-free electrocatalyst. Nat Commun 2014, 5, 3783.

52. Sun, D. M.; Liu, C.; Ren, W. C.; Cheng, H. M., All-carbon thin-film transistors as a step towards flexible and transparent electronics. Advanced Electronic Materials 2016, 2 (11), 1600229.

53. Fellinger, T.-P.; Su, D. S.; Engenhorst, M.; Gautam, D.; Schlögl, R.; Antonietti, M., Thermolytic synthesis of graphitic boron carbon nitride from an ionic liquid precursor: mechanism, structure analysis and electronic properties. Journal of Materials Chemistry 2012, 22 (45), 23996-24005.

54. Gong, J.; Antonietti, M.; Yuan, J., Poly(lonic Liquid)-Derived Carbon with Site-Specific N-Doping and Biphasic Heterojunction for Enhanced CO2 Capture and Sensing. Angewandte Chemie International Edition 2017, 56 (26), 7557-7563.

55. Qi, D.; Liu, Y.; Liu, Z.; Zhang, L.; Chen, X., Design of Architectures and Materials in In-Plane Microsupercapacitors: Current Status and Future Challenges. Advanced Materials 2017, 29 (5), 1602802.

56. Mazzanti, S.; Manfredi, G.; Barker, A. J.; Antonietti, M.; Savateev, A.; Giusto, P., Carbon Nitride Thin Films as All-In-One Technology for Photocatalysis. ACS Catalysis 2021, 11 (17), 11109-11116.

57. Faisal, S. N.; Haque, E.; Noorbehesht, N.; Zhang, W.; Harris, A. T.; Church, T. L.; Minett, A. I., Pyridinic and graphitic nitrogen-rich graphene for high-performance supercapacitors and metal-free bifunctional electrocatalysts for ORR and OER. RSC advances 2017, 7 (29), 17950-17958.

58. Inagaki, M.; Toyoda, M.; Soneda, Y.; Morishita, T., Nitrogen-doped carbon materials. Carbon 2018, $132,104-140$. 